\title{
Thermoelectric Power Generation using Waste-Heat Energy from Internal Combustion Engine
}

\author{
D. T. Kashid ${ }^{*}$, S. H. Barhatte ${ }^{\ddagger}$ and D. S. Ghodake ${ }^{\dagger}$ \\ †Mechanical Engineering Department, SVERI's College of Engineering, Pandharpur, Maharashtra, India \\ ¥Mechanical Engineering Department, MAEER's MIT College of Engineering, Kothrud, Pune, Maharashtra, India \\ Accepted 01 March 2016, Available online 15 March 2016, Special Issue-4 (March 2016)
}

\begin{abstract}
The efficiency in an internal combustion engine ranges from 25\% to 35\%. About $40 \%$ of the overall fuel energy losses in a combustion engine are waste heat which is blown out with the exhaust gases and 30\% is cooled away by the vehicle's radiator. Even if a small fraction of the waste heat could be turned into useful energy again it would be a step in the right direction of improving fuel economy. Being one of the promising new devices for an automotive waste heat recovery, thermoelectric generators (TEG) are used now days. This paper focuses on generation of electrical energy with the help of thermoelectric power generator. Thermoelectric modules are used to convert thermal energy from a temperature gradient to electrical energy and it works on basic principle of Seebeck effect. Hence the selection of thermoelectric materials plays very important role for energy conversion in thermoelectric applications. Sizing up the heat exchanger is based on the size, orientation, and number of modules. After designing suitable heat exchanger, the thermoelectric modules are integrated on the heat exchanger for performance analysis. In this work, the effort is on the performance of thermoelectric generator under various engine operating conditions like engine speed, mass flow rate of exhaust gas.
\end{abstract}

Keywords: Engine Exhaust, Figure of merit, Insulation, Seebeck Effect, Thermoelectric Module, Thermoelectric Generator, Waste Heat Recovery.

\section{Introduction}

Most engines operate with an efficiency rate of about $30 \%$, with most of the wasted energy lost as heat. There is an increased need to identify alternative energy sources and enhance the efficiency of engines in order to reduce the consumption of fuel. The purpose of this project is to examine whether lost energy can be recovered in the form of electricity to power the electrical components of a vehicle. Thermoelectric Power generator will be analyzed as possible solutions to recover this lost energy in order to improve the overall engine efficiency.

Study on automobiles gasoline powered internal combustion engine shows that only approximate $25 \%$ $35 \%$ of the fuel energy is used to drive the engine, whereas $40 \%$ of the fuel energy is wasted in exhaust gas, $30 \%$ in engine coolant and $5 \%$ in friction and parasitic losses (Fig.1).

If the waste heat can recover, not only the every Ringgit spends for fuel is become more valuable, but also can reduce the fuel consumption due to less fuel require to generate electric for vehicle.

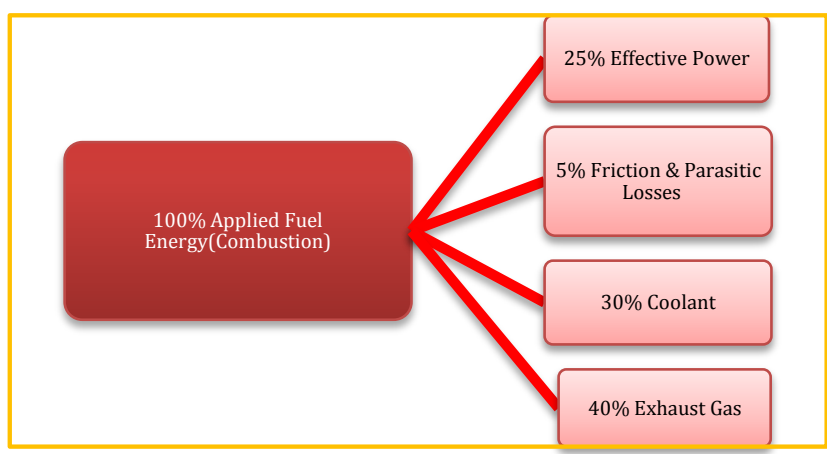

Fig.1 Energy Split in I.C. Engines

As a conclusion, the increasing of oil prices in the world market and low utilization of gasoline powered engine makes it necessary to generate new sustainable sources of electric power in modern automobiles. Furthermore, vehicle nowadays requires more and more electricity energy in order to maintain the communication, navigation, engine control, and safety systems of the vehicle. Therefore TEG is the best solution to recover waste heat through converts the heat energy into electricity. The focus of this project is to design a TEG system which can integrate into the automobile vehicle to generate electricity. 


\subsection{Thermoelectric Power Generator}

The basic theory and operation of thermoelectric based systems have been developed for many years. Thermoelectric power generation is based on a phenomenon called "Seebeck effect" discovered by Thomas Seebeck in 1821. When a temperature difference is established between the hot and cold junctions of two dissimilar materials (metals or semiconductors) a voltage is generated, i.e., Seebeck voltage. In fact, this phenomenon is applied to thermocouples that are extensively used for temperature measurements. Based on this Seebeck effect, thermoelectric devices can act as electrical power generators.

Fig.2 (Basel et al, 2009) shows a schematic diagram illustrating components and arrangement of a conventional thermoelectric power generator. As shown in figure, it is composed of two ceramic plates (substrates) that serve as a foundation, providing mechanical integrity, and electrical insulation for ntype (heavily doped to create excess electrons) and ptype (heavily doped to create excess holes) semiconductor thermoelements. In thermoelectric materials, electrons and holes operate as both charge carriers and energy carriers. The ceramic plates are commonly made from alumina $\left(\mathrm{Al}_{2} \mathrm{O}_{3}\right)$, but when large lateral heat transfer is required, materials with higher thermal conductivity (e.g. beryllium and aluminum nitride) are desired. The semiconductor thermoelements (e.g. silicon-germanium SiGe, leadtelluride $\mathrm{PbTe}$ based alloys) that are sandwiched between the ceramic plates are connected thermally in parallel and electrically in series to form a thermoelectric device (module). More than one pair of semiconductors are normally assembled together to form a thermoelectric module and within the module a pair of thermoelements is called a thermocouple. The junctions connecting the thermoelements between the hot and cold plates are interconnected using highly conducting metal (e.g. copper) strips.

The potential of a material for thermoelectric applications is determined in large part to a measure of the material's dimensionless figure of merit (ZT). Semiconductors have been primarily the materials of choice for thermoelectric applications. There are challenges in choosing suitable materials with sufficiently higher ZT for the applications.

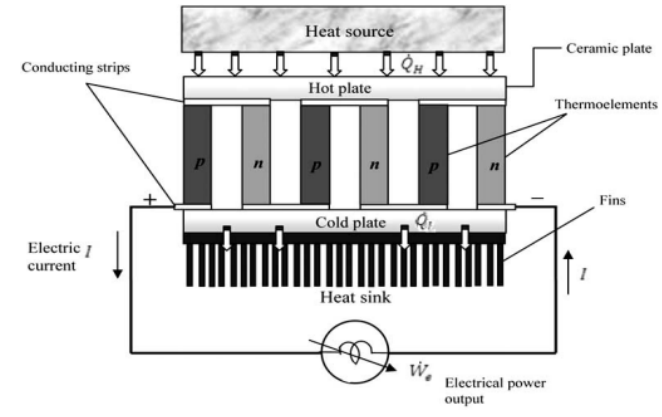

Fig. 2 Components and arrangement of a typical single-stage thermoelectric power generator

\subsection{Figure of merit}

The performance of thermoelectric materials can be expressed as

$\mathrm{Z}=\frac{\alpha^{2}}{\mathrm{kR}}$

$\mathrm{Z}$ is the thermoelectric material figure-of-merit, $\alpha$ is the Seebeck coefficient given by,

$\alpha=\frac{\Delta V}{\Delta \mathrm{T}}$

$\mathrm{R}$ is the electric resistivity (inverse of electric conductivity) and $\mathrm{k}$ is the total thermal conductivity.

The figure of merit depends on the properties of thermoelectric material used. A high value of $\mathrm{Z}$ is obtained by using materials of large seebeck coefficient, small thermal conductivity and small electrical resistivity. This figure-of-merit may be made dimensionless by multiplying by $\overline{\mathrm{T}}$ (average absolute temperature of hot and cold plates of the thermoelectric module, $\mathrm{K}$ ),

i.e.

$$
\begin{aligned}
& \mathrm{Z} \overline{\mathrm{T}}=\frac{\alpha^{2} \overline{\mathrm{T}}}{\mathrm{kR}} \\
& \overline{\mathrm{T}}=\frac{\mathrm{T}_{\mathrm{H}}+\mathrm{T}_{\mathrm{L}}}{2}
\end{aligned}
$$

The term $\frac{\alpha^{2}}{\mathrm{kR}}$ is referred to as the electrical power factor. In general, a thermoelectric power generator exhibits low efficiency due to the relatively small dimensionless figure-of-merit $\quad(\mathrm{ZT} \leq 1)$ of currently available thermoelectric materials. The conversion efficiency of a thermoelectric power generator defined as the ratio of power delivered to the heat input at the hot junction of the thermoelectric device, is given by,

$$
n=\frac{\mathrm{w}_{\mathrm{e}}}{\mathrm{Q}_{\mathrm{H}}}
$$

The maximum conversion efficiency of an irreversible thermoelectric power generator can be estimated using,

$n_{\text {ideal }}=\left(1-\frac{\mathrm{T}_{\mathrm{L}}}{\mathrm{T}_{\mathrm{H}}}\right)\left[\frac{\mathrm{M}-1}{\mathrm{M}+\frac{\mathrm{T}_{\mathrm{L}}}{\mathrm{T}_{\mathrm{H}}}}\right]$

Where,

$M=\left[1+\frac{\mathrm{Z}}{2}\left(\mathrm{~T}_{\mathrm{H}}+\mathrm{T}_{\mathrm{L}}\right)\right]^{1 / 2}$

The value of the figure-of-merit is usually proportional to the conversion efficiency. The dimensionless term $\mathrm{ZT}$ is therefore a very convenient figure for comparing the potential conversion efficiency of modules using different thermoelectric materials. 


\section{Design of Thermoelectric Power Generation} System

\subsection{Selection of Suitable Thermoelectric Material}

Among the vast number of materials known to date, only a relatively few are identified as thermoelectric materials. Thermoelectric materials can be categorized into established (conventional) and new (novel) materials. Today's most thermoelectric materials, such as Bismuth Telluride $\left(\mathrm{Bi}_{2} \mathrm{Te}_{3}\right)$-based alloys and $\mathrm{PbTe}$ based alloys, have a $\overline{Z T}$ value of around unity (at room temperature for $\mathrm{Bi}_{2} \mathrm{Te}_{3}$ and $500-700 \mathrm{~K}$ for $\mathrm{PbTe}$ ). However, at a $Z \overline{\mathrm{T}}$ of $2-3$ range, thermoelectric power generators would become competitive with other power generation systems. The figure-of merit of a number of thermoelectric materials together with potential power generating applications relevant to waste heat energy is shown in Fig.3 (Basel et al, 2009). Effective thermoelectric materials should have a low thermal conductivity but a high electrical conductivity.

A large amount of research in thermoelectric materials has focused on increasing the Seebeck coefficient and reducing the thermal conductivity, especially by manipulating the nanostructure of the thermoelectric materials. Because the thermal and electrical conductivity correlate with the charge carriers, new means must be introduced in order to conciliate the contradiction between high electrical conductivity and low thermal Conductivity.

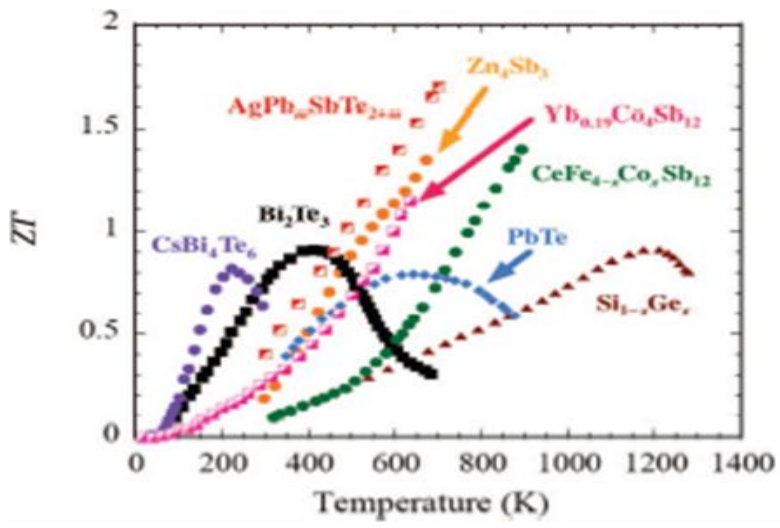

Fig.3 Figure of merit ZT shown as a function of temperature for several bulk thermoelectric materials

Thermoelectric materials (those which are employed in commercial applications) can be conveniently divided into three groupings based on the temperature range of operation, as shown in table 1 . Although the above mentioned materials still remain the cornerstone for commercial and practical applications in thermoelectric power generation, significant advances have been made in synthesising new materials and fabricating material structures with improved thermoelectric performance. However the proportion of heat supplied that is converted into electrical energy is only about $5 \%$ to $7 \%$. Efforts have focused primarily on improving the material's figureof-merit, and hence the conversion efficiency.
Table 1 Temperature range for thermoelectric materials

$\begin{array}{cc}\text { Temperature range } & \text { Thermoelectric material } \\ \text { up to around 450K. } & \begin{array}{c}\text { Alloys based on Bismuth (Bi) in } \\ \text { combinations with Antimony (Sn), } \\ \text { Tellurium (Te) or Selenium (Se) }\end{array} \\ \text { up to around } 850 \mathrm{~K} & \text { based on alloys of Lead (Pb) } \\ \text { up to } 1300 \mathrm{~K} . & \text { SiGe alloys }\end{array}$

\subsubsection{Performance analysis of selected thermoelectric material}

Bismuth Telluride $\left(\mathrm{Bi}_{2} \mathrm{Te}_{3}\right)$

The maximum value of figure of merit,

$\mathrm{Z}_{\max }=3 \times 10^{-3} \mathrm{~K}^{-1}$

The optimum value of the resistance ratio,

$\mathrm{M}=\left[1+\frac{\mathrm{z}}{2}\left(\mathrm{~T}_{\mathrm{H}}+\mathrm{T}_{\mathrm{L}}\right)\right]^{1 / 2}$

Where,

$\mathrm{T}_{\mathrm{H}}=$ temperature of the source $(\mathrm{K})$

$\mathrm{T}_{\mathrm{L}}=$ temperature of the $\operatorname{sink}(\mathrm{K})$

$\mathrm{T}_{\mathrm{H}}=400 \mathrm{~K} \quad \mathrm{~T}_{\mathrm{L}}=315 \mathrm{~K}$

By putting above values in equation,

$\mathrm{M}=\left[1+\frac{3 \times 10^{-3}}{2}(400+315)\right]^{1 / 2}$

We get, $\quad M=1.4396$

We know that, the maximum or ideal thermal efficiency of a thermoelectric convertor is given by,

$n_{\text {th } \max }=\left(1-\frac{\mathrm{T}_{\mathrm{L}}}{\mathrm{T}_{\mathrm{H}}}\right)\left[\frac{\mathrm{M}-1}{\mathrm{M}+\frac{\mathrm{T}_{\mathrm{L}}}{\mathrm{T}_{\mathrm{H}}}}\right]$

By putting above values in given equation,

$n_{\text {th } \max }=\left(1-\frac{315}{400}\right)\left[\frac{1.4396-1}{1.4396+\frac{315}{400}}\right]$

We get, maximum thermal efficiency is

$n_{\text {th } \max }=0.083130=8.313 \%$

$\mathrm{Bi}-\mathrm{Te}$ is one of the easy available materials with highest value of $\alpha$, low cost. Also the position of TEG system is just behind the catalyst converter. All the TEGs designed to be mounted in this position are based on bismuth telluride alloys. It minimizes the amount of heat transfer surface required. This decreases the pressure drop across the generator and results in a lower back pressure. Hence we have selected Bismuth Telluride as TEG material.

\subsection{Design of Hot Side Heat Exchanger}

The overall heat exchanger model is in need of an increase in heat transfer effectiveness. To enable more heat to be channeled into the thermoelectric modules, finned heat exchangers are needed. The increase in surface area increases convection which in turn increases the heat transferred to or from the fluid depending on which side of the heat exchanger the fins are on. An appropriately selected material with high 
thermal conductivity is needed to maintain an effective level of conduction. When more heat is transferred to the TEG more power is removed from the system and thus, generated by the heat exchanger.

Many fin options are available and selection of a configuration is dependent on several reasons. The overall intent of the finned heat exchangers is to increase surface area which will increase heat transfer. However, the increase in surface area will increase the pressure drop of the flow of fluid passing over the heat exchangers. This substitution needs to be balanced as part of the design of the fin assemblies. The design also needs to reflect material and manufacturing costs. Before the extended surfaces can be modelled, the size of the heat exchanger unit must be determined.

Sizing up the heat exchanger is based on the size, orientation, and number of modules. Instead of finding the whole heat exchanger size, the size of an individual zone is to be found and then extended to represent the entire heat exchanger. First, the length and width of all the modules combined within a zone is to be determined. Because the modules are assumed to be square as they often are, length and width differ by the number of modules defined by flow orientation. $\mathrm{N}_{\text {mod,par }}$ (no. of modules in parallel) and $\mathrm{N}_{\text {mod,ser }}$ (no. of modules in series)exist to help in developing the orientation of the modules in a zone. $\mathrm{W}_{\text {mod,zone }}$ is the width of all the modules in a zone if they were side by side. $\mathrm{L}_{\text {mod,zone }}$ is the length of all of the modules in a zone if they were directly adjacent to each other.

Module size: $40 \times 40 \times 3.4 \mathrm{~mm}$

$$
\begin{aligned}
& \mathrm{L}_{\text {mod,zone }}=\mathrm{W}_{\text {mod }} \times \mathrm{N}_{\text {mod,ser }} \\
& \mathrm{L}_{\text {mod,zone }}=40 \times 2=80 \mathrm{~mm} \\
& \mathrm{~W}_{\text {mod,zone }}=\mathrm{W}_{\text {mod }} \times \mathrm{N}_{\text {mod,par }} \\
& \mathrm{W}_{\text {mod,zone }}=40 \times 1=40 \mathrm{~mm}
\end{aligned}
$$

These parameters can be used to develop two more equations and important values. $A_{\text {mod,zone }}$ is the surface area of all the modules in the zone and $\beta_{\text {lw }}$ is the ratio of the length of all the modules in the zone to the width of all the modules in the zone. These two parameters, in addition to a user input, can now be used to determine the dimensions of the zone. It is required that the user define the ratio of the total zone surface area to $A_{\text {mod,zone, }}$

$\mathrm{A}_{\text {mod,zone }}=\mathrm{L}_{\text {mod,zone }} \times \mathrm{W}_{\text {mod,zone }}$

$\mathrm{A}_{\text {mod,zone }}=80 \times 40=3200 \mathrm{~mm}^{2}$

$\beta_{\mathrm{lw}}=\frac{\mathrm{L}_{\text {mod,zone }}}{\mathrm{W}_{\text {mod,zone }}}=\frac{80}{40}=2$

$A_{\text {zone }}$ is the surface area of a zone and $\gamma$ is the user defined ratio for zone area to modules in a zone area. If it is defined as one, then there is no insulation surrounding the modules within a zone. If it is greater than one, there is considered to be insulation surrounding the modules and the insulation is adjacent to the modules on all sides. It fills in the lengths and widths not defined as module length or width. The exact length and width of each stretch of insulation is not needed to be known. $\gamma$ is always greater than or equal to one by its definition. We take it as $2 . A_{\text {ins }}$ is the area of the insulation.

$$
\begin{aligned}
& A_{\text {zone }}=\gamma \times A_{\text {mod,zone }}=2 \times 3200=6400 \mathrm{~mm}^{2} \\
& A_{\text {ins }}=A_{\text {zone }}-A_{\text {mod,zone }}=6400-320=3200 \mathrm{~mm}^{2}
\end{aligned}
$$

Two more important calculations that define zone dimensions are needed. They are length and width of the zone itself, insulation included. Now that area of a zone is known and the total module length to total module width ratio is known, it is rather simple to calculate zone length and zone width.

$$
\begin{aligned}
& \mathrm{L}_{\mathrm{z}}=\sqrt{\beta_{\mathrm{lw}} \times \mathrm{A}_{\text {zone }}}=120 \mathrm{~mm} \\
& \mathrm{~W}_{\mathrm{z}}=\sqrt{\frac{1}{\beta_{\mathrm{lw}}} \times \mathrm{A}_{\text {zone }}}=60 \mathrm{~mm}
\end{aligned}
$$

$L_{z}$ is the length of an entire zone and $W_{z}$ is the width of a zone. These are used throughout the calculations of the finned heat exchangers and are necessary for defining various fin dimensions. Therefore final dimension of Hot side heat sink $=120 \times 60 \mathrm{~mm}$.

\subsubsection{Design of Rectangular Straight Fins}

Rectangular straight fins are very common fin geometry because of their simplicity to manufacturer. They are commonly available in different sizes and can be mounted to other structures fairly easily. Their simplicity also makes for a good starting place in describing their relation to the methods used in TEG. The initial set up of the fins and their geometry requires a few input parameters.

Number of fins $\left(\mathrm{N}_{\mathrm{f}}\right)=8$

Number of channels $\left(\mathrm{N}_{\mathrm{ch}}\right)=\mathrm{N}_{\mathrm{f}}-1=7$

Thickness of an individual fin $\left(\mathrm{T}_{\mathrm{f}}\right)=2 \mathrm{~mm}$

The length of an individual fin $\left(\mathrm{L}_{\mathrm{f}}\right)=26 \mathrm{~mm}$

Thickness of the base $\left(\mathrm{T}_{\mathrm{b}}\right)=7 \mathrm{~mm}$

\section{1) Pitch of Fin $\left(P_{f}\right)$}

The pitch of a fin is needed to be known to help determine the spacing between fins. The pitch helps to keep the fins constrained to the size of the heat exchanger.

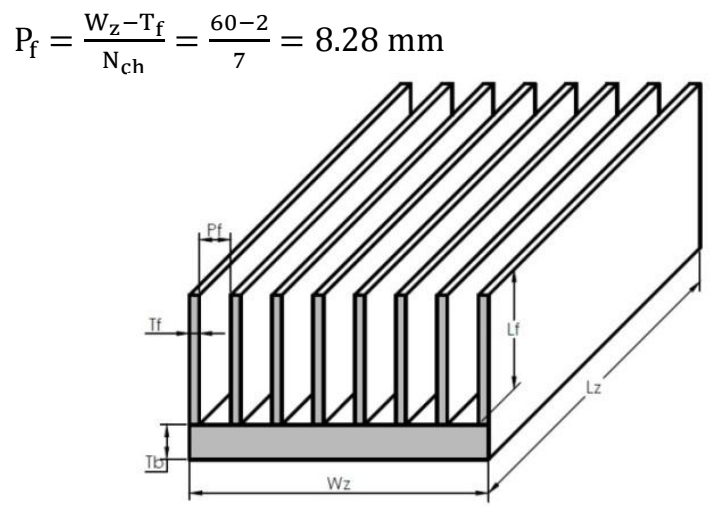

Fig.4 Rectangular Heat Exchanger Geometry 


\section{2) Spacing between fins $\left(\mathrm{S}_{\mathrm{f}}\right)$}

The spacing between fins is used for several calculations because it represents part of the dimensioning of the flow path.

$\mathrm{S}_{\mathrm{f}}=\mathrm{P}_{\mathrm{f}}-\mathrm{T}_{\mathrm{f}}=8.28-2=6.28 \mathrm{~mm}$

3) Wetted Perimeter, $\left(\mathrm{P}_{\text {wet }}\right)$

$\mathrm{P}_{\text {wet }}$, is the perimeter of a flow path or one channel created by the fins.

$\mathrm{P}_{\text {wet }}=2\left(\mathrm{~L}_{\mathrm{f}}+\mathrm{S}_{\mathrm{f}}\right)=2(26+6.28)=64.57 \mathrm{~mm}$

4) Hydraulic diameter $\left(D_{h}\right)$

The wetted perimeter of the fin is known, it is now possible to find the hydraulic diameter. It is an artificial diameter representing the channel in which flow travels through.

$\mathrm{D}_{\mathrm{h}}=\frac{4 \times \mathrm{L}_{\mathrm{f}} \times \mathrm{S}_{\mathrm{f}}}{\mathrm{P}_{\mathrm{wet}}}=\frac{4 \times 26 \times 6.28}{64.57}=10.11 \mathrm{~mm}$

5) An entrance area, $\left(A_{\text {ent }}\right)$

An entrance area needs to be considered for the flow paths through the rectangular straight fins.

$A_{\text {ent }}=S_{\mathrm{f}} \times \mathrm{L}_{\mathrm{f}} \times \mathrm{N}_{\mathrm{ch}}=6.28 \times 26 \times 7=1142.96 \mathrm{~mm}^{2}$

6) The characteristic length of the fin, $\left(L_{f, c h a r}\right)$

This is needed for fin efficiency calculations.

$\mathrm{L}_{\mathrm{f}, \text { char }}=\mathrm{L}_{\mathrm{f}}+\frac{\mathrm{T}_{\mathrm{f}}}{2}=26+\frac{2}{2}=27 \mathrm{~mm}$

7) The perimeter of the face of the fin, $\left(\mathrm{P}_{\text {face }}\right)$ :

It is needed to support in finding the efficiency of the proposed fin.

$P_{\mathrm{f}}=2\left(\mathrm{~T}_{\mathrm{f}}+\mathrm{L}_{\mathrm{z}}\right)=2(2+120)=244 \mathrm{~mm}$

8) The cross sectional area of the fin, $\left(A_{c}\right)$

$A_{c}=T_{f} \times L_{z}=2 \times 120=240 m^{2}$

This value is also used in calculating the efficiency of the designed fin.

9) The total surface area of all the fins, $\left(A_{f, \text { surf }}\right)$

The total surface area of all the fins is needed for finding the total surface area that is affected by convection.

$\mathrm{A}_{\mathrm{f}, \text { surf }}=2 \times \mathrm{N}_{\mathrm{ch}} \times \mathrm{L}_{\mathrm{f}, \text { char }} \times \mathrm{L}_{\mathrm{z}}$

$\mathrm{A}_{\mathrm{f} \text {,surf }}=2 \times 7 \times 27 \times 120=45360 \mathrm{~mm}^{2}$

10) The total area of the base, $\left(A_{b, s u r f}\right)$

The total area of the base, Ab,surf, is also needed to help find the total effective surface area.
$A_{b, \text { surf }}=A_{\text {zone }}-\left(A_{C} \times N_{f}\right)$

$A_{b, \text { surf }}=6400-(240 \times 7)=4480 \mathrm{~mm}^{2}$

11) Total effective surface area, $A_{\text {tot,surf }}$ :

Total effective surface area, $A_{\text {tot,surf }}$, is the area which fluid flow occurs and convective heat transfer is present.

$A_{\text {tot,surf }}=A_{f, \text { surf }}+A_{b, \text { surf }}$

$A_{\text {tot,surf }}=45360+4480=49840 \mathrm{~mm}^{2}$

Now that the fins have been designed, their performance needs to be evaluated.

\subsection{Design of Cold Side Heat Sink}

From various permutations and combinations, we selected stacked type heat sink for cold side.

\subsubsection{Design of Cold Side Heat Sink Stacks}

Number of fins $\left(\mathrm{N}_{\mathrm{f}}\right)=11$

Number of channels $\left(\mathrm{N}_{\mathrm{ch}}\right)=\mathrm{Nf}-1=10$

Thickness of an individual fin $\left(\mathrm{T}_{\mathrm{f}}\right)=2 \mathrm{~mm}$

The length of heat sink $=\mathrm{K} \times$ (length of hot side heat exchanger) $=1.5 \times 120=180 \mathrm{~mm}$

The width of heat sink $=62 \mathrm{~mm}$

The length of an individual fin $\left(\mathrm{L}_{\mathrm{f}}\right)=14 \mathrm{~mm}$

Thickness of the base $\left(T_{b}\right)=5 \mathrm{~mm}$

Number of stacks $=2$

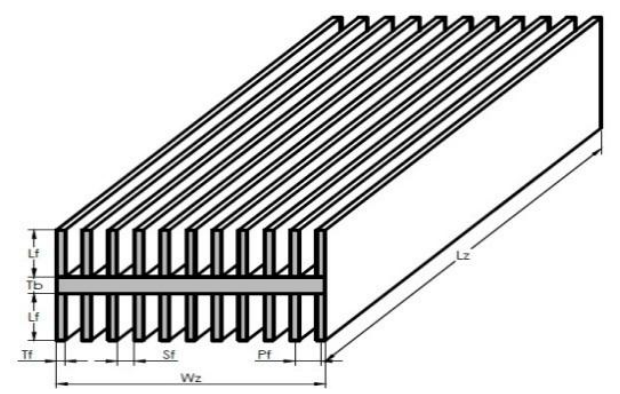

Fig.5 Double Stacked Type Cold Side Heat Sink

1) Pitch of Fin $\left(P_{f}\right)$

$\mathrm{P}_{\mathrm{f}}=\frac{\mathrm{W}_{\mathrm{z}}-\mathrm{T}_{\mathrm{f}}}{\mathrm{N}_{\mathrm{ch}}}=\frac{62-2}{10}=6 \mathrm{~mm}$

2) Spacing between fins $\left(\mathrm{S}_{\mathrm{f}}\right)$

$\mathrm{S}_{\mathrm{f}}=\mathrm{P}_{\mathrm{f}}-\mathrm{T}_{\mathrm{f}}=6-2=4 \mathrm{~mm}$

3) Wetted Perimeter, (Pwet)

$\mathrm{P}_{\mathrm{wet}}=2\left(\mathrm{~L}_{\mathrm{f}}+\mathrm{S}_{\mathrm{f}}\right)=2(14+4)=36 \mathrm{~mm}$

4) Hydraulic diameter $\left(D_{h}\right)$

$\mathrm{D}_{\mathrm{h}}=\frac{4 \times \mathrm{L}_{\mathrm{f}} \times \mathrm{S}_{\mathrm{f}}}{\mathrm{P}_{\mathrm{wet}}}=\frac{4 \times 14 \times 4}{36}=6.22 \mathrm{~mm}$

5) An entrance area, $\left(A_{\text {ent }}\right)$ 
$A_{\text {ent }}=S_{f} \times L_{f} \times N_{c h}=4 \times 14 \times 10=560 m^{2}$

6) The characteristic length of the fin, $\left(L_{f, c h a r}\right)$

$\mathrm{L}_{\mathrm{f}, \mathrm{char}}=\mathrm{L}_{\mathrm{f}}+\frac{\mathrm{T}_{\mathrm{f}}}{2}=14+\frac{2}{2}=15 \mathrm{~mm}$

7) The perimeter of the face of the fin, $\left(\mathrm{P}_{\text {face }}\right)$

$P_{f}=2\left(T_{f}+L_{z}\right)=2(2+180)=364 m m$

8) The cross sectional area of the fin, $\left(A_{c}\right)$

$A_{c}=T_{f} \times L_{z}=2 \times 180=360 \mathrm{~mm}^{2}$

9) The total surface area of all the fins, $\left(A_{f, s u r f}\right)$

$\mathrm{A}_{\mathrm{f} \text {,surf }}=2 \times \mathrm{N}_{\mathrm{ch}} \times \mathrm{L}_{\mathrm{f} \text {,char }} \times \mathrm{L}_{\mathrm{z}}$

$\mathrm{A}_{\mathrm{f} \text {,surf }}=2 \times 10 \times 15 \times 180=54000 \mathrm{~mm}^{2}$

10) The total area of the base, $\left(A_{b, s u r f}\right)$

$A_{\text {b,surf }}=A_{\text {zone }}-\left(A_{C} \times N_{f}\right)$

$A_{b, \text { surf }}=11160-(360 \times 11)=7200 \mathrm{~mm}^{2}$

11) Total effective surface area, $A_{\text {tot,surf }}$

$A_{\text {tot,surf }}=A_{f, \text { surf }}+A_{b, \text { surf }}$

$A_{\text {tot,surf }}=54000+7200=61200 \mathrm{~mm}^{2}$

As we are selected double stacks here, the capacity gets doubled.

\subsection{Material Selection for Thermal Insulation}

The arrangement of thermoelectric module is sandwich type in between hot side heat exchanger and cold side heat sink. Hence, there is a need of thermal insulation for the area which is not covered by thermoelectric modules to avoid heat loss.

$\mathrm{A}_{\text {ins }}=\mathrm{A}_{\text {zone }}-$ Amod,zone

$A_{\text {ins }}=6400-3200$

$\mathrm{A}_{\text {ins }}=3200 \mathrm{~mm}^{2}$

Selection of material for insulation: Ceramic pads

Temperature range- above $500{ }^{\circ} \mathrm{C}$

Thermal conductivity: $\mathrm{k}=0.15 \mathrm{~W} / \mathrm{mk}$

Hence ceramic pads are selected for highest temperature range, low thermal conductivity. Also it can be cut into required size and shape easily.

\section{Manufacturing \& Assembly}

\subsection{Aluminium Welding}

We have designed Heat exchangers rectangular in shape. Our requirement was to flow fluid through it without any kind of leakage. Hence aluminium TIG welding is suitable to the ends of both heat exchangers.
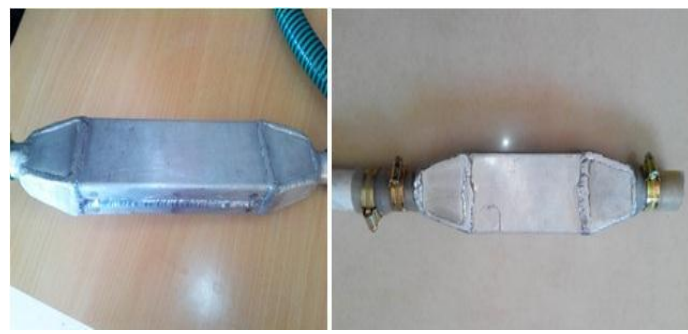

Fig.6 Aluminium Welding of Heat Exchangers

\subsection{Assembly}

The heat exchangers are assembled with the sandwich arrangement of thermoelectric modules between them as shown in fig.7. Before assembly the thermal grease is applied on both the surfaces of TEG modules to enhance the heat transfer. Ceramic pads are inserted between the exchangers for insulation for the area not covered by modules. Counter flow type arrangement is made for the heat exchangers. Two ' $\mathrm{C}$ ' clamps are used for clamping of heat exchangers. Thermocouples (KType) are connected along with the display for temperature measurement.

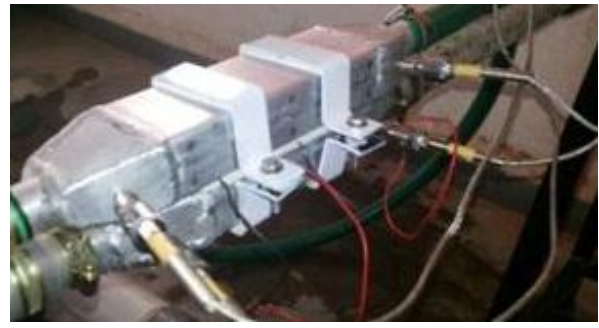

Fig.7 Assembly of heat exchangers with modules

\section{Experimental Setup}

After successful assembly of heat exchangers, TEG System is attached on a 3 cylinder, 4 stroke, Petrol Engine test rig. Experimental Setup is ready to take sets of trials at different engine speed. As a load on system, LED load bank is used. Using the thermocouples; temperatures at 6 sections are measured on Digital temperature indicator. Then voltage \& current at various engine speeds are measured on Digital multimeter.

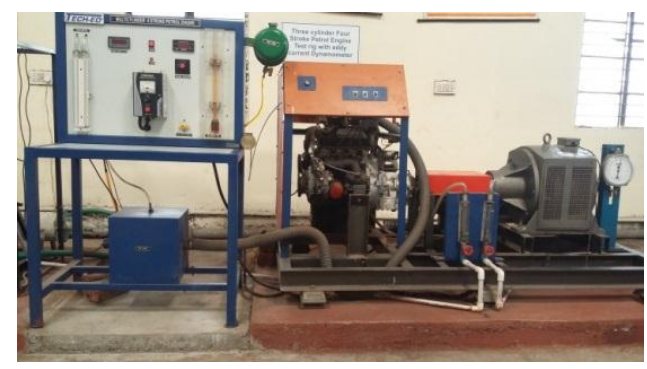

Fig.8 Three cylinder, four stroke, Petrol Engine test Rig with TEG System 


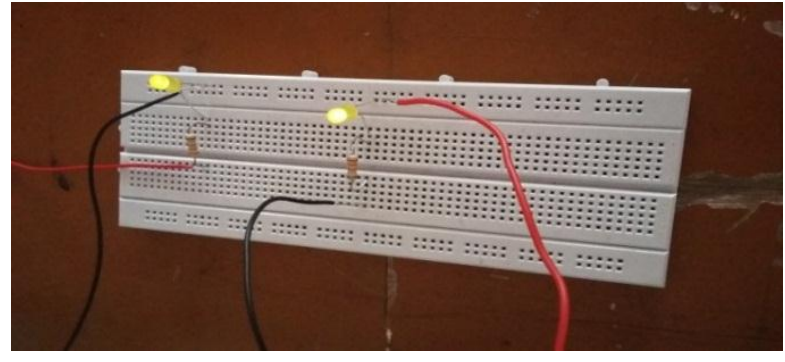

Fig.9 LED Load Bank for TEG System

\section{Calculations}

$\mathrm{T}_{1}=$ Hot side inlet temperature

$\mathrm{T}_{2}=$ Hot side outlet temperature

$\mathrm{T}_{3}=$ Cold side inlet temperature

$\mathrm{T}_{4}=$ Cold side outlet temperature

$\mathrm{T}_{\mathrm{in}}=$ Exhaust gas temperature at TEG system inlet

$\mathrm{T}_{\mathrm{ex}}=$ Exhaust gas temperature at TEG system exit

Table 2 Experimental Observation Table

\begin{tabular}{|c|c|c|c|c|c|c|c|c|c|c|}
\hline ? & 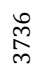 & $\stackrel{\vec{J}}{\underset{\sim}{*}}$ & 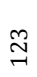 & 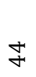 & \& & ஜ̊ & $\begin{array}{l}\infty \\
m \\
m\end{array}$ & นొน & $\hat{\vec{m}}$ & $\begin{array}{l}\stackrel{\rho}{1} \\
\text { m. }\end{array}$ \\
\hline$\sigma$ & $\begin{array}{l}\stackrel{\infty}{2} \\
\stackrel{m}{m}\end{array}$ & $\underset{ָ}{\mathbb{N}}$ & $\stackrel{\infty}{=}$ & $q$ & $\stackrel{2}{+}$ & $\begin{array}{l}\infty \\
\infty \\
m\end{array}$ & $\stackrel{\infty}{m}$ & ma & 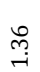 & 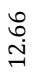 \\
\hline$\infty$ & $\begin{array}{c}\text { Oे } \\
\text { di }\end{array}$ & $\exists$ & $\stackrel{\Omega}{=}$ & $\mathcal{F}$ & $\dot{F}$ & $\underset{m}{\stackrel{\Omega}{m}}$ & $\stackrel{\sigma}{m}$ & 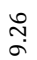 & $\underset{\rightarrow}{m}$ & $\underset{\text { I }}{\text { I }}$ \\
\hline$\wedge$ & $\begin{array}{l}\text { D. } \\
\text { m }\end{array}$ & $\underset{\exists}{ \pm}$ & $\underset{\exists}{\exists}$ & $\mathcal{F}$ & F & $\underset{m}{\mathbb{N}}$ & m్ర & $\begin{array}{l}\sigma \\
\infty \\
\infty\end{array}$ & $\tilde{\sim}$ & $\begin{array}{l}\overrightarrow{7} \\
\vec{z}\end{array}$ \\
\hline 0 & $\begin{array}{l}\infty \\
\text { m } \\
\text { ma }\end{array}$ & $\exists$ & $\stackrel{\circ}{\circ}$ & $\mathcal{F}$ & F & $\overrightarrow{0}$ & N & $\begin{array}{l}q \\
\infty \\
\infty\end{array}$ & $\stackrel{\sim}{\underset{H}{\sim}}$ & $\stackrel{0}{0}$ \\
\hline เก & $\begin{array}{l}\infty \\
\stackrel{\infty}{m} \\
\vec{m}\end{array}$ & $\stackrel{\infty}{\stackrel{0}{\sim}}$ & $\underset{\theta}{\hat{\theta}}$ & $F$ & $\mathscr{F}$ & in & $\underset{m}{\mathcal{F}}$ & مִ & $\underset{ت}{\stackrel{+}{*}}$ & $\underset{\infty}{\stackrel{m}{\infty}}$ \\
\hline+ & ஜे & 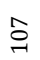 & $\stackrel{2}{\stackrel{2}{0}}$ & $F$ & $\mathscr{m}$ & 암 & $\underset{m}{n}$ & $\stackrel{\text { f }}{r}$ & $\underset{7}{F}$ & $\begin{array}{c}\stackrel{\infty}{\infty} \\
\infty\end{array}$ \\
\hline$m$ & $\begin{array}{l}\text { L్ } \\
\underset{N}{N}\end{array}$ & $\stackrel{2}{0}$ & $\underset{\sim}{\stackrel{\theta}{\sigma}}$ & $\not$ & भ & m & స్లి & 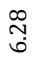 & 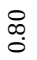 & $\begin{array}{l}\vec{b} \\
\text { in }\end{array}$ \\
\hline$N$ & 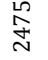 & 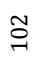 & $\stackrel{0}{~}$ & $F$ & भ & $\stackrel{\circ}{\text { mे }}$ & d্ & : & 角 & $\vec{m}$ \\
\hline$r$ & 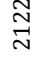 & g & ó & 아 & ₹ & $\stackrel{\infty}{\stackrel{\infty}{N}}$ & $\stackrel{m}{N}$ & $\begin{array}{l}\underset{N}{n} \\
\text { in }\end{array}$ & กิ & $\stackrel{\sqrt{\mathrm{N}}}{ }$ \\
\hline $\begin{array}{l}\dot{z} \\
\text { i. }\end{array}$ & 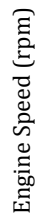 & $\underset{F}{\vec{E}}$ & 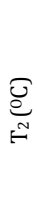 & 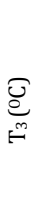 & 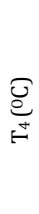 & 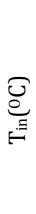 & 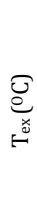 & 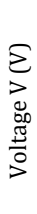 & 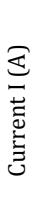 & 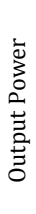 \\
\hline
\end{tabular}

\section{Results \& Discussions}

\subsection{Voltage Vs Engine Speed}

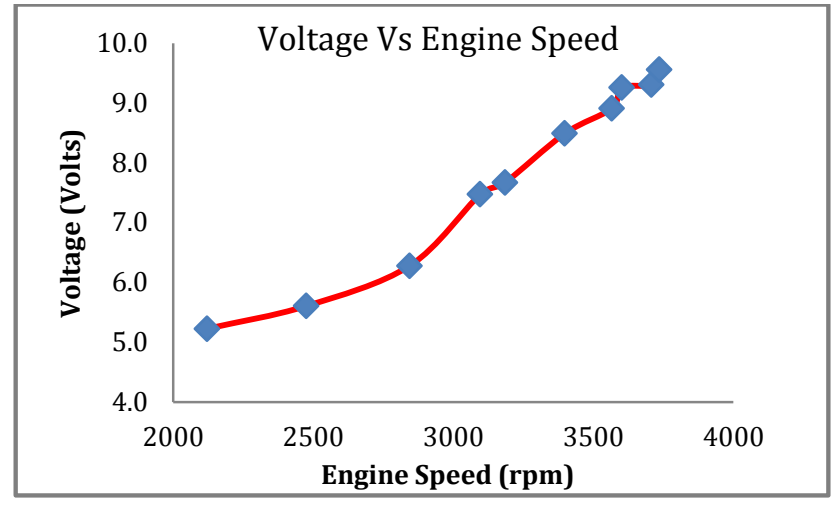

Fig.10 Voltage Vs Engine Speed

The graph shows that as the engine speed increases voltage generated also increases. Hence voltage is proportional to engine speed. With the engine speed of $3736 \mathrm{rpm}$, voltage generated is 9.56 Volts.

Table 3 Result Table

\begin{tabular}{|c|c|c|c|c|c|c|}
\hline $\begin{array}{c}\text { Sr. } \\
\text { No. }\end{array}$ & $\begin{array}{c}\text { Engine } \\
\text { Speed } \\
\text { (rpm) }\end{array}$ & $\begin{array}{c}\mathrm{m}_{\text {ex }} \times 10^{-3} \\
(\mathrm{~kg} / \mathrm{sec})\end{array}$ & $\begin{array}{c}\text { Temp. } \\
\mathrm{drop} \\
\Delta T= \\
\left(T_{\text {in }}-\right. \\
\left.T_{\text {ex }}\right)\end{array}$ & $\begin{array}{c}\text { Input } \\
\text { Power } \\
P_{\text {in }}= \\
m_{\text {ex }} \times \\
C_{P} \times \Delta \\
(\mathrm{W})\end{array}$ & $\begin{array}{c}\text { Ouput } \\
\text { Power } \\
P_{\text {out }} \\
=\times I \\
(\mathrm{~W})\end{array}$ & $\begin{array}{c}\text { TEG } \\
\text { Overall } \\
\text { Efficiency } \\
\eta=\frac{P_{\text {out }}}{P_{\text {in }}} \\
(\%)\end{array}$ \\
\hline 1 & 2122 & 16.394 & 5 & 91.31 & 2.710 & 2.97 \\
\hline 2 & 2475 & 17.326 & 6 & 105.6 & 3.178 & 3.01 \\
\hline 3 & 2845 & 19.894 & 7 & 149.2 & 5.018 & 3.36 \\
\hline 4 & 3096 & 21.987 & 8 & 179.4 & 8.287 & 4.62 \\
\hline 5 & 3186 & 22.417 & 8 & 182.9 & 8.738 & 4.78 \\
\hline 6 & 3398 & 23.912 & 9 & 219.5 & 10.64 & 4.85 \\
\hline 7 & 3566 & 23.987 & 9 & 234.7 & 11.71 & 4.99 \\
\hline 8 & 3603 & 24.007 & 10 & 244.8 & 12.31 & 5.03 \\
\hline 9 & 3708 & 24.013 & 10 & 244.9 & 12.66 & 5.17 \\
\hline 10 & 3736 & 24.317 & 10 & 248.0 & 13.10 & 5.28 \\
\hline
\end{tabular}

6.2 Current Vs Engine Speed

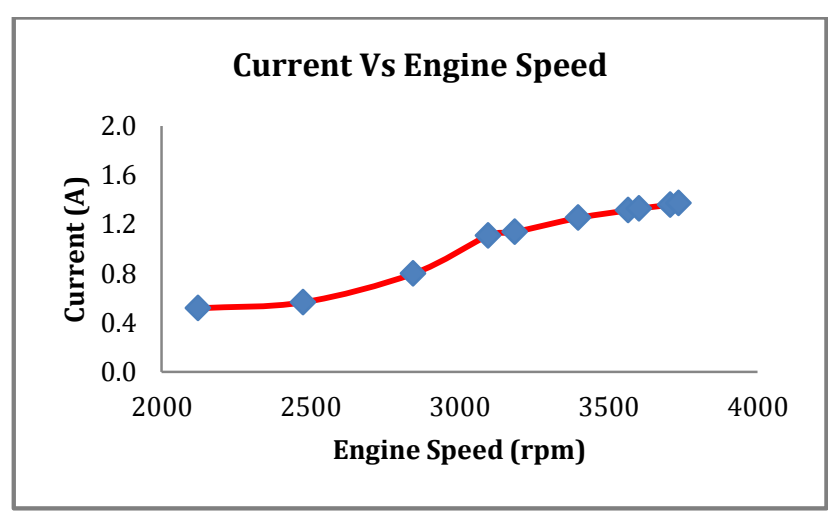

Fig.11 Current Vs Engine Speed plot

The graph explains that the current increases with the engine speed. It first increases gradually up to 2845 rpm then rapidly beyond that speed. At the speed of $3736 \mathrm{rpm}$ the current is 1.37 Amperes. 


\subsection{Power output Vs Engine Speed}

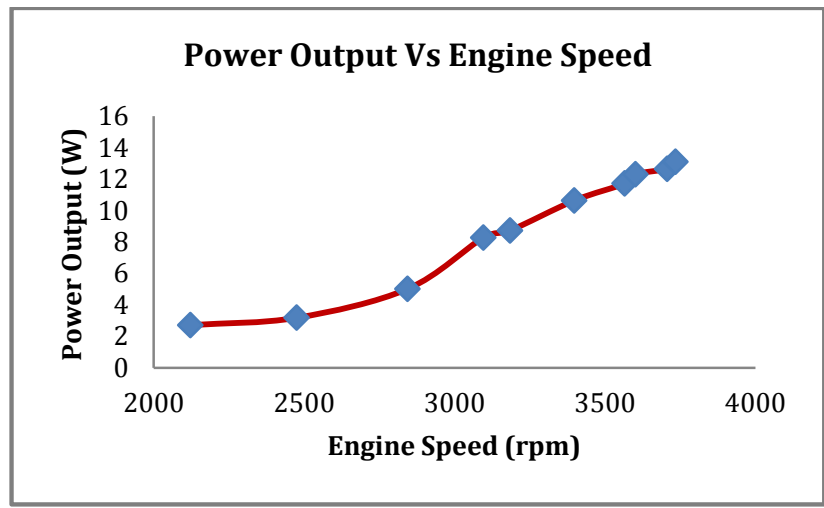

Fig.12 Power output Vs Engine Speed

The graph shows that the power output is function of engine speed. At the speed of $3736 \mathrm{rpm}$, the power developed by TEG system is $13.106 \mathrm{~W}$.

6.4 TEG Overall Efficiency Vs Engine Speed

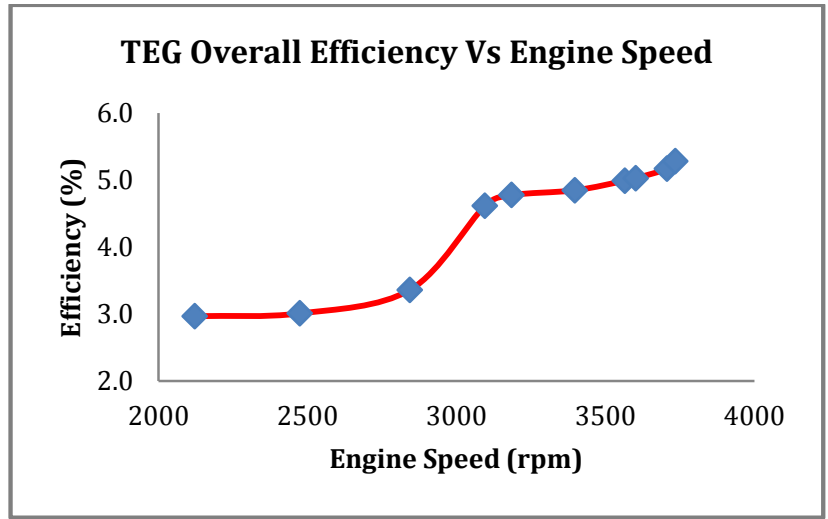

Fig.13 Efficiency Vs Engine Speed

The graph explains the relation between the overall efficiency of the system and engine speed. At $3736 \mathrm{rpm}$ the efficiency obtained is $5.28 \%$.

\subsection{TEG Output Power Vs Input Power of Exhaust Gas}

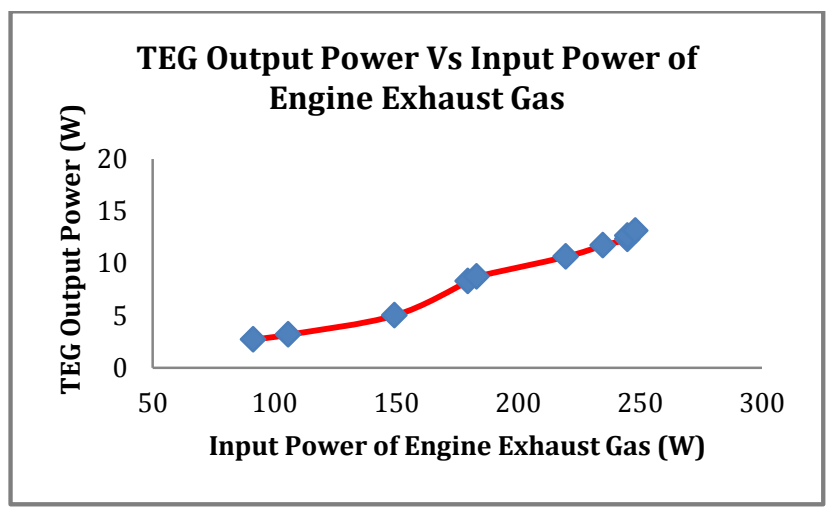

Fig.13 TEG Output Power Vs Input Power

The graph shows that at the engine speed of $3736 \mathrm{rpm}$, input power of engine exhaust gas is $248.03 \mathrm{~W} \&$ the
TEG output power is $13.106 \mathrm{~W}$, hence the overall efficiency obtained is $5.28 \%$.

\subsection{Power Output Vs Mass Flow Rate of Exhaust Gas}

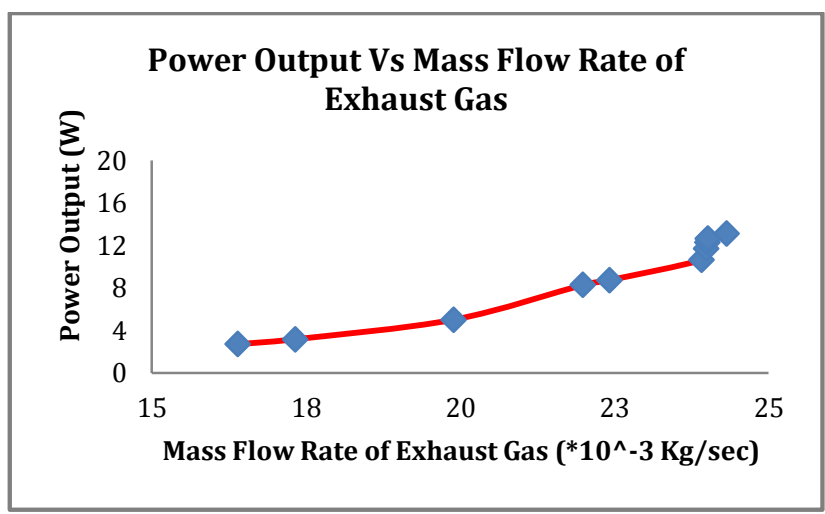

Fig.14 Power Output Vs Mass Flow Rate of Exhaust Gas

The graph shows that the power output is function of mass flow rate of exhaust gas. At the mass flow rate of exhaust gas of $24.317 \times 10^{-3} \mathrm{Kg} / \mathrm{sec}$, the power developed by TEG system is $13.106 \mathrm{~W}$.

\section{Conclusions}

1. At high vehicle speeds, the total power that could be extracted is increased.

2. More power could also be extracted by improving the exhaust gas heat exchanger.

3. Results show that voltage, current, power developed and efficiency of the system increase with the increase in engine speed \& mass flow rate of exhaust gas.

4. At the engine speed of $3736 \mathrm{rpm}$, the power generated is $13.106 \mathrm{~W}$ and efficiency of the system is $5.28 \%$

5. Hence the TEG system traps the waste heat of exhaust gases from engine \& generates useful power which can be used to charge the automobile batteries, to power auxiliary systems and minor automobile electronics system.

6. As this system recovers the lost energy in exhaust of the engine therefore the overall efficiency increases.

\section{References}

Crane D.T., Bell L.E. (2009), Design to Maximize Performance of a Thermoelectric Power Generator With a Dynamic Thermal Power Source, Journal of Energy Resources Technology, Vol. 131/012401-8.

Basel I.I. and Wael H. A.(2009), Thermoelectric power generation using waste-heat energy as an alternative green technology, Recent patents on electrical engineering, 2(1), pp.27-29.

Liang G., Zhou J., Huang X. (2011), Analytical model of parallel thermoelectric generator, Applied Energy, 88, pp.51935199.

C. Ramesh Kumar, Sonthalia A., Goel R. (2011), Experimental Study on Waste Heat Recovery from an Internal 
Combustion Engine Using Thermoelectric Technology, Thermal Science, 15(4), pp. 1011-1022.

Hsu C., Huang G., Chu H., Yu B., Yao D. (2011), Experiments and simulations on low-temperature waste heat harvesting system by thermoelectric power generators, Applied Energy , 88, pp.1291-1297.

Dai D., Zhou Y., Liu J. (2011), Liquid metal based thermoelectric generation system for waste heat recovery, Renewable Energy, 36, pp.3530-3536.

Love N.D., Szybist J.P., Sluder C.S. (2012), Effect of heat exchanger material and fouling on thermoelectric exhaust heat recovery, Applied Energy, 89, pp.322-328.

Weng C., Huang M. (2013), A simulation study of automotive waste heat recovery using a thermoelectric power generator, International Journal of Thermal Sciences, 71, pp.302-309.

Schock H., Brereton G. et al. (2013), Prospects for Implementation of Thermoelectric Generators as Waste Heat Recovery Systems in Class 8 Truck Applications, Journal of Energy Resources Technology, Vol. 135 / 022001-9.

Tian Z., Lee S., Chen G. (2013), Heat Transfer in Thermoelectric Materials and Devices, Journal of Heat Transfer, Vol.135/061605-15.

Wang Y., Dai C., Wang S.(2013), Theoretical analysis of a thermoelectric generator using exhaust gas of vehicles as heat source, Applied Energy, 112, pp.1171-1180.
Jang J., Tsai Y. (2013), Optimization of thermoelectric generator module spacing and spreader thickness used in a waste heat recovery system, Applied Thermal Engineering 51, pp.677-689.

X. Liu et al. (2014), Experiments and simulations on heat exchangers in thermoelectric generator for automotive application, Applied Thermal Engineering, 71, pp. 364-370.

C. Q. Su, W. S. Wang, X. Liu, Y. D. Deng (2014), Simulation and experimental study on thermal optimization of the heat exchanger for automotive exhaust-based thermoelectric generators, Case Studies in Thermal Engineering, 4, pp.8591.

Liang X. et al. (2014), Comparison and parameter optimization of a two-stage thermoelectric generator using high temperature exhaust of internal combustion engine, Applied Energy, 130, pp.190-199.

Freedman A. P., A Thermoelectric Generation Subsystem Model for Heat Recovery Simulations , M.S. Thesis, Rochester Institute of Technology, pp. 13-16, 24 ,31, 93101 .

V. Ganesan (2009), Internal Combustion Engines , pp. 576, Third Edition, pub.-Tata McGraw-hill.

Rajput R. K. (2009), Heat and Mass Transfer , Third Edition, pub.-Tata McGraw-hill.

Rai G. D. (2010), Non-Conventional Energy Sources , Fourth Edition, pp. 720-722, Khanna Publishers. 